\title{
Investigation of the apparent kinetics of air and oxy-fuel biomass combustion in a spouted fluidised-bed reactor
}

\author{
Yongliang Yan ${ }^{\mathrm{a}}$, Peter T. Clough ${ }^{\mathrm{a}}$, Edward J. Anthony ${ }^{\mathrm{a} *}$ \\ ${ }^{a}$ Energy and Power Theme, Cranfield University, Cranfield, Bedfordshire, MK43 0AL, UK \\ * Corresponding Author: Edward J. Anthony, E: b.j.anthony@cranfield.ac.uk, Tel: +44 (0) 1234752823
}

\begin{abstract}
A bench-scale spouted fluidised-bed reactor was used to investigate the combustion kinetics of pulverised woody biomass under air and oxy-fuel atmospheres. Bed temperatures were in the range of 923-1073 $\mathrm{K}$ and $\mathrm{O}_{2}$ concentrations were varied from 20-35 vol\%. The activation energies and apparent orders of reaction were calculated for air and oxy-fuel combustion by means of an $\mathrm{n}^{\text {th }}$ order Arrhenius equation approach. Results indicated that the apparent order of reaction for both air and oxy-fuel combustion was approximately zero. The activation energies were calculated assuming a zero-order reaction mechanism and were averaged over all oxygen concentrations for air and oxy-fuel combustion and found to be $18.95 \mathrm{~kJ} / \mathrm{mol}$ and $26.93 \mathrm{~kJ} / \mathrm{mol}$, respectively. The rate of combustion under oxy-fuel conditions was, on average, $37.5 \%$ higher compared to air combustion. The shrinking core model with a reaction-controlled step was found to accurately represent the biomass combustion reactions under both air and oxy-fuel conditions.
\end{abstract}

\section{Keywords}

Combustion; Kinetics; Biomass; Oxy-fuel; Spouted fluidised bed; Carbon capture and storage 


\section{Introduction}

Carbon capture and storage (CCS) is a significant technology to reduce the environmental burden of fossil fuel use (Bui et al., 2018). More recently, the combination of Bio-Energy with CCS (BECCS) has drawn global attention in the context of greenhouse gas (GHG) emissions reduction (Sher et al., 2018). Oxy-fuel combustion is a promising technology with a Technology Readiness Level (TRL) of 7-8 for carbon capture from power generation and industry (Seddighi et al., 2018). In particular, fluidised bed (FB) is one of the more promising technologies that can apply an oxy-fuel based approach, which has the benefits of fuel flexibility, low $\mathrm{SO}_{\mathrm{x}}$ and $\mathrm{NO}_{\mathrm{x}}$ emissions, and a reduced energy penalty. Burning biomass under oxy-fuel conditions provides the option of $\mathrm{CO}_{2}$-negative emissions as well as offering other advantages such as improving ignition and burnout performance and reducing the pollutant emissions when co-firing with coal (Duan et al., 2015). Biomass with oxy-fuel combustion technology is a potential BECCS technology.

However, there are significant differences between coal and biomass with respect to combustion kinetics and, hence, design and operation of a boiler (Seddighi et al., 2018; Varol et al., 2018; Zhu, 2013). Therefore, it is necessary to study the kinetics of the air and oxy-fuel combustion of biomass before deploying BECCS at a large scale. The derived and calculated kinetic parameters from an experimental study can be used for computational fluid dynamics calculations, to help design and optimise commercial-scale boilers for air and oxy-fuel combustion of biomass (Gil et al., 2012).

The kinetics study of solid fuels is conducted in a range of equipment, including: the thermogravimetric analyser (TGA) (Liu, 2009; Wang et al., 2015), drop-tube reactor (DTR) (Tolvanen et al., 2016; Tolvanen and Raiko, 2014), entrained-flow reactor (EFR) (Álvarez et al., 2011), wire-mesh reactor (WMR) (Kim et al., 2017), and fluidised-bed reactors (FBR) (Fennell et al., 2009, 2007, 2005; Gövert et al., 2017).

TGA kinetic analysis allows direct measurement of sample mass, with high repeatability. However, the low heating rates and the effects of the heat and mass transfer influence the accuracy of the experimental results and are generally regarded as problematic when determining intrinsic kinetic parameters (Gövert et al., 2017; Kim et $a l ., 2017)$. EFR and WMR by contrast, have complicated measurement and analysis and require a skilled operator which limits their application (Fennell et al., 2009). Aside from these techniques, other researchers (Fennell et al., 2009; Gövert et al., 2017) have proposed using a bench-scale fluidised-bed reactor (FBR) with a fast-response gas analyser to investigate the kinetics of char combustion. This method can provide homogeneous temperature and bulk gas composition, high heating rates (around $10^{4} \mathrm{~K} / \mathrm{s}$ ), sufficient residence time, flexible temperature and gas compositions and an approximate carbon mass balance (Kim et al., 2017; Li et al., 2015; Mueller et al., 2015). However, this method relies on any reaction of the sample being inferred by measuring the gas composition rather than directly measuring the weight change of the sample itself, thus opening itself up to errors. It is also difficult to extract and quench fuel samples during a combustion experiment to permit the analysis of morphology and composition evolution, which are possible for EFR and DTR (Kim et al., 2017; Mueller et al., 2015). 
Bews et al. first determined the kinetic parameters and reaction mechanism of the combustion of graphite using a small FBR (Bews et al., 2001). Subsequently, Fennell et al. (2009) further developed this method to study the kinetics of burning of coal char in a FBR with a fast-response gas analyser of $\mathrm{CO} / \mathrm{CO}_{2}$ (Álvarez et al., 2011; Haustein et al., 2015). More recently, Haustein et al. also used a small-scale FBR with Fourier Transform Infrared (FTIR) spectroscopy to study the kinetic parameters of char combustion and gasification (Haustein et al., 2015). Similarly, Gövert et al. measured and compared the kinetic parameters of coal char combustion and gasification under air/oxy-fuel combustion using the same reactor and noted that the reaction of char in air was faster than in oxy-fuel atmosphere, and that there is no significant difference in activation energies in air and oxy-fuel combustion (Gövert et al., 2017). Generally, it has been found that the results obtained through FBRs can be comparable those obtained from EFRs and TGAs, once the minimisation of mixing effects and fast analysers are employed (Fennell et al., 2009; Gövert et al., 2017; Mueller et al., 2015).

Compared with the existing kinetic studies of coal char combustion for FBR, there is a dearth of literature regarding air and oxy-fuel combustion of biomass when employing a FBR. Much of the previous work has focused on the kinetically-controlled oxidation reaction of char in different oxidising gases (Fennell et al., 2009; Gövert et al., 2017; Haustein et al., 2015; Morin et al., 2018). The apparent kinetics of air and oxy-fuel combustion of raw biomass by the FBR method and the effects of devolatilisation and volatile matter combustion on the kinetics measurement of char have not been well investigated. In this work, a bench-scale spouted fluidised-bed reactor operating in bubbling fluidisation mode with a fast-response multi-gas analyser has been used to investigate the apparent kinetics of air and oxy-fuel combustion of woody biomass with the aim of exploring the effects of devolatilisation and volatile matter combustion on the overall kinetics of biomass combustion.

\section{Materials and methods}

\subsection{Materials}

Here, ECOTEK wood pellets were ground, with a pestle and mortar, and sieved to a particle size fraction of 300$425 \mu \mathrm{m}$, and then stored in sealed sample containers. The proximate analysis of the pulverised wood was conducted with a TGA 8000 (Perkin Elmer) using the method reported in Cai et al. (2017), which was proven to yield similar results to those obtained from the ASTM standard method. The ultimate analysis of the fuel sample was measured by a Vario EL III Elemental Analyser. The proximate and ultimate analyses of the biomass are given in Table 1.

For the bed material, silica sand (bulk density $=2600 \mathrm{~kg} / \mathrm{m}^{3}$, rounded to sub-rounded in shape, supplied by David Ball Group Plc.) and sieved to a size fraction of 425-500 $\mu \mathrm{m}$, was used. For the fluidising gases, $\mathrm{CO}_{2}, \mathrm{O}_{2}$ and $\mathrm{N}_{2}$ (supplied by BOC UK) of respective purities $99.8 \%, 99.5 \%$ and $99.998 \%$, were used in these experiments. 
Table 1. Proximate and ultimate analyses of biomass sample.

\begin{tabular}{cc}
\hline Proximate analysis (wt\%, as received) \\
\hline Moisture & 4.97 \\
Volatile matter & 78.30 \\
Fixed carbon & 14.93 \\
Ash content & 1.79 \\
\hline Ultimate analysis (wt\%, as received) \\
\hline C & 47.91 \\
H & 6.70 \\
$\mathrm{~N}$ & 0.12 \\
$\mathrm{~S}$ & 0.04 \\
O (by difference) & 45.27 \\
\hline
\end{tabular}

2.2 Experimental setup

A process flow diagram of the bench-scale spouted fluidised reactor and ancillary equipment is shown in Figure 1. A quartz liner (240 mm in length, $26 \mathrm{~mm}$ O.D., supplied by Soham Scientific, Cambridge, UK) was placed inside the main body of the reactor and was made of a cylindrical section with a conical frustum at the base $(8 \mathrm{~mm}$ I.D.). The reactor was heated by electrical resistance heating and its temperature was measured by K-type thermocouples on the outer wall of the reactor and inside the bed's quartz liner. The reactor shell was constructed of Incoloy $800 \mathrm{HT}$ (supplied by Special Metals, UK) and had a total length of $500 \mathrm{~mm}$, an outer diameter of 31.8 $\mathrm{mm}$ and a wall thickness of $2.9 \mathrm{~mm}$.

The reactor was designed to facilitate the addition of solid fuels through a U-bend and pressurised batch feeding system. The U-bend and gas supply tubes after the mass flow controls were wrapped with heating tapes and heated to $105^{\circ} \mathrm{C}$ in order to preheat the gas and fuels before entering the reactor. Superwool insulating blanket (supplied by RS Components Ltd, UK) was utilised to minimise heat loss.

Three mass flow controllers (MFCs) (Bronkhorst EL-FLOW model F-201CV) controlled the gas flow rate of $\mathrm{N}_{2}$, $\mathrm{CO}_{2}$ and $\mathrm{O}_{2}$. All the MFCs can be controlled by a computer via a dynamic data exchange field bus based on RS485 technology (Bronkhorst Flow BUS) to realise automatic control of the flow in the various gas transport lines and simulate different gas mixtures at the gas mixing point.

Finally, a series of gas filters was installed to clean the flue gas leaving the reactor, particularly to remove fine particulate matter and moisture. A portion of the gas was then diverted to the ADC multi-gas analyser (MGA 3000, ADC Ltd., UK), and the remaining gases were sent to the exhaust gas ventilation system. The analyser measured the concentrations of $\mathrm{O}_{2}, \mathrm{CO}$ and $\mathrm{CO}_{2}$ from the flue gas and the measurement ranges of these gases were 0-40 vol\%, 0-20 vol\% and 0-100 vol\%, respectively, and their intrinsic accuracy was $\pm 1 \%$ of the measured value. The 
humidity content in the flue gas was measured with a relative humidity probe (Vaisala HUMICAP HMT330). An Agilent VEE process controller and data recording system was used for this work; data were passed to this system from data acquisition (DAQ) cards (RedLab USB-1208FS, Meilhaus Electronic).

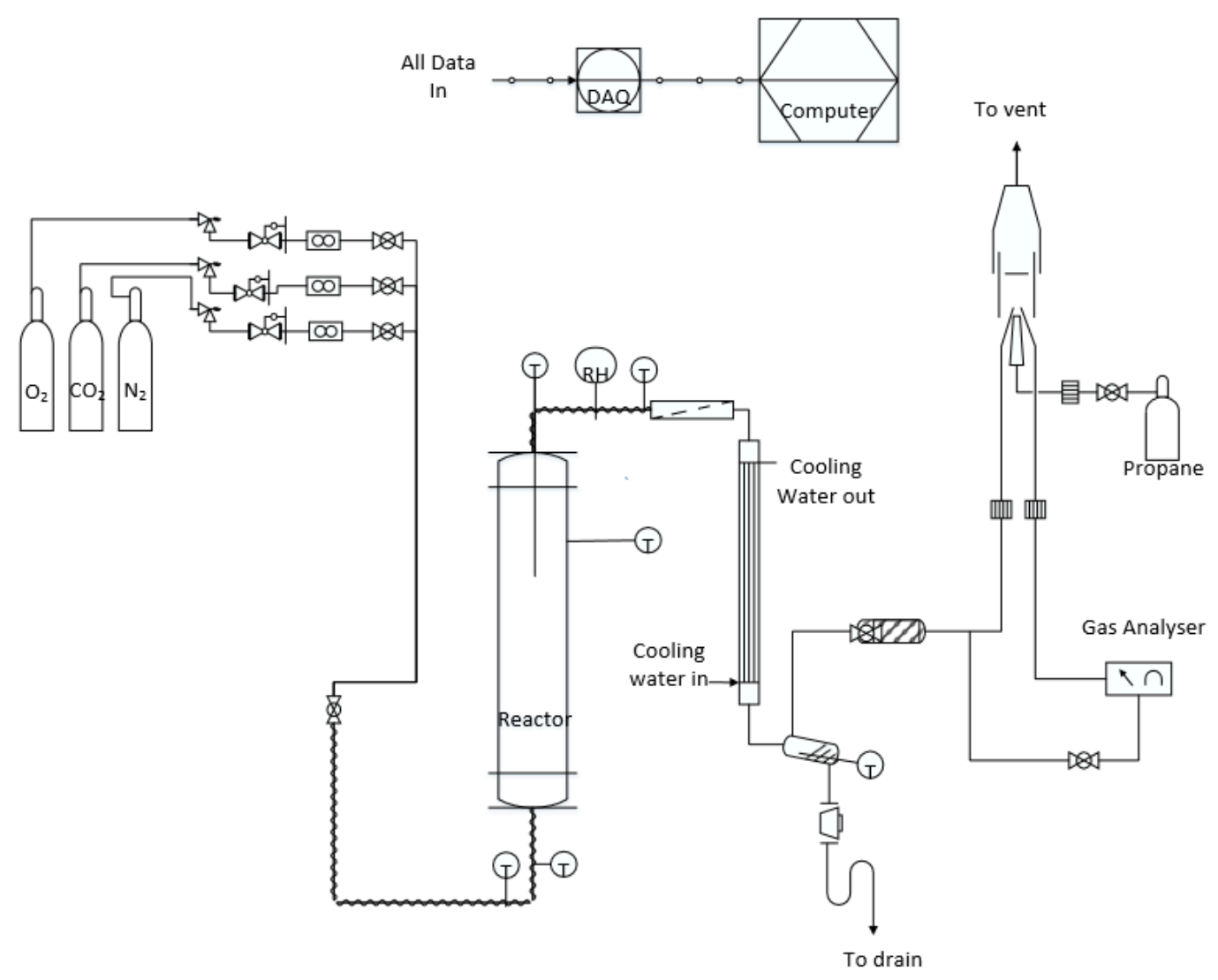

Figure 1. Process flow diagram of the spouted fluidised-bed reactor and ancillary equipment.

\subsection{Standard operating procedure}

The experiments were conducted at atmospheric pressure in a temperature range of 923-1073 K. Typically, $15 \mathrm{~g}$ of silica sand $(425-500 \mu \mathrm{m})$ was added into the reactor when the reactor reached the desired temperature and had a uniform gas concentration. The oxygen concentration in the air and oxy-fuel combustion tests was varied from $20 \mathrm{vol} \%$ to $35 \mathrm{vol} \%$ and balanced with $\mathrm{N}_{2}$ and $\mathrm{CO}_{2}$, respectively. A small amount of $\mathrm{N}_{2}$ (5 vol\%) was added to each of the oxy-fuel tests to ensure an accurate mass balance could be achieved; it was assumed that the $\mathrm{N}_{2}$ was inert in these combustion tests. The detailed operation conditions are shown in Table S.1. (See Supplementary Materials).

The minimum fluidisation velocity $\left(U_{\mathrm{mf}}\right)$ was calculated using the Wen and $\mathrm{Yu}$ correlation (Wen and $\mathrm{Yu}, 1966$ ). To ensure sufficiently vigorous bubbling fluidisation and to improve the gas-solid mixing inside the reactor, a ratio of fluidisation velocity $(U)$ to minimum fluidisation velocity ( $U / U_{\mathrm{mf}}$ ) of $\sim 3$ was employed. Fuel sample masses of $0.02 \mathrm{~g}( \pm 2 \%)$ were injected into the reactor via the pressurised feeding system, once the bed temperature and gas 
concentrations were at steady state. An assessment of the correct sample mass was made, the data from which is presented in the Supplementary Materials section; the aim was to select the smallest mass which presented a readable signal relative to the background noise level of the analyser and was closest in observed rate to the assumed intrinsic rate of the smallest sample mass. As the amount of silica sand was much greater than that of the injected fuel sample, this ensured good heat transfer between bed material and injected fuel sample allowing the fuel to rapidly achieve similar temperatures. Furthermore, a high cross-flow factor (see Supplementary Materials for more details) was calculated for this system, which indicated that the gas concentration in the bubble phase and particle phase were nearly the same, and there was a high degree of mixing within the bed. Each test was repeated three times at each set of conditions, and a blank test (no biomass sample only inert gas $\left(\mathrm{N}_{2}\right)$ added during feeding) was repeated before and after every sample injection, which was used to indicate whether the sample was fully injected into the reactor, and to quantify the effects of sample injection on the measured gas concentrations (see Supplementary Materials for more details). Any blank test where the hold-up prevented 100\% of the sample from being completely introduced into the reactor, was repeated after cleaning the valve and sample hopper. In addition, the average carbon recovery based on $\mathrm{CO}_{2}$ was calculated for each condition to ensure elutriation of the fuel samples was minimised. To achieve the real-time measured gas concentration, it is necessary to consider the response time of the test rig. In this work, the deconvolution of the measured gas concentration was dealt with a published method by Fennell et al. (2009). The response time of this test rig was calculated to be around $2.29 \mathrm{~s}$ and the details of calculation can be found in the Supplementary Materials.

\section{Results and Discussion}

\subsection{Reaction rates}

The dynamic response of the gas analysers measured concentrations, caused pressurised sample injection, were corrected to obtain the actual rate of gas production (further detail is supplied in the Supplementary Materials, Fig. S.4-S.6). The peak rates of biomass combustion were assumed approximately equivalent to the initial rate of reaction. During some initial tests it was found that, below $20 \mathrm{vol} \% \mathrm{O}_{2}$, the rate of $\mathrm{CO}$ production exceeded that of $\mathrm{CO}_{2}$ production (Figure 2), due to sub-stoichiometric conditions leading to incomplete combustion; therefore, the data at $10 \mathrm{vol} \% \mathrm{O}_{2}$ were excluded from the analysed data set. The $\mathrm{O}_{2}$ concentration was varied from 20-35 vol\% at intervals of 5 vol\% for both air and oxy-fuel combustion tests. 

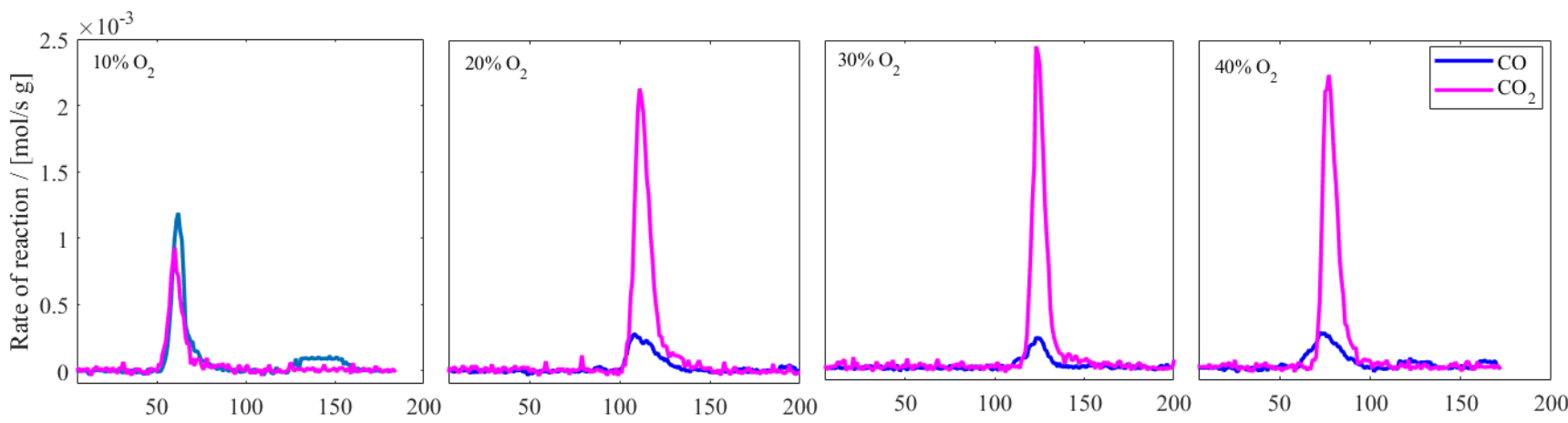

Time/s

Figure 2. Rate of biomass combustion in $10-40 \mathrm{vol} \% \mathrm{O}_{2}$. At conditions of $973 \mathrm{~K}, \mathrm{U} / \mathrm{U}_{\mathrm{mf}}=3,0.02 \mathrm{~g}( \pm 2 \%)$

biomass, and 1 bar(a).

The combustion rates for air and oxy-fuel combustion for pulverised wood and recovery of carbon are summarised in Table S.2 (see Supplementary Materials). Figure 3 and Figure 4 give the rates of $\mathrm{CO}_{2}$ production $v s$. bed temperature and oxygen concentration, both of which indicate that the rates of $\mathrm{CO}_{2}$ production increase with the increase of the bed temperature. The measured rate with different sample weights at conditions of $823 \mathrm{~K}, 25 \mathrm{vol} \%$ $\mathrm{O}_{2} / 75 \operatorname{vol} \% \mathrm{~N}_{2}, \mathrm{U} / \mathrm{U}_{\mathrm{mf}}=3$, and 1 bar(a) are compared in Fig. S.7 in the Supplementary Materials. It is clearly shown that the sample mass added had no effect on the rate of reaction, for sample masses greater than $0.02 \mathrm{~g}$. The sample mass was selected to maximise the signal to noise ratio and use a little sample as possible in order to minimise intraparticle diffusion effects which could hamper the rate of reaction. Comparing the rates of air and oxy-fuel combustion at the same bed temperature and oxygen concentration shows that the rate of oxy-fuel combustion is about 20-30\% larger than that of air combustion, which is opposite to the results reported for air and oxy-fuel combustion of coal char (Gövert et al., 2017). It is also worth pointing out that carbon balance for oxy-fuel combustion is higher than that of the air combustion of raw woody biomass when the bed temperature is over $923 \mathrm{~K}$, which means that the burnout rate of fuel could be improved when switching from air to oxy-fuel combustion at those conditions. The average carbon recovery for both air and oxy-fuel combustion of biomass was approximately $80 \%$, without considering the $\mathrm{CO}$ and $\mathrm{CH}_{4}$ produced, which indicates there was negligible particle elutriation. 


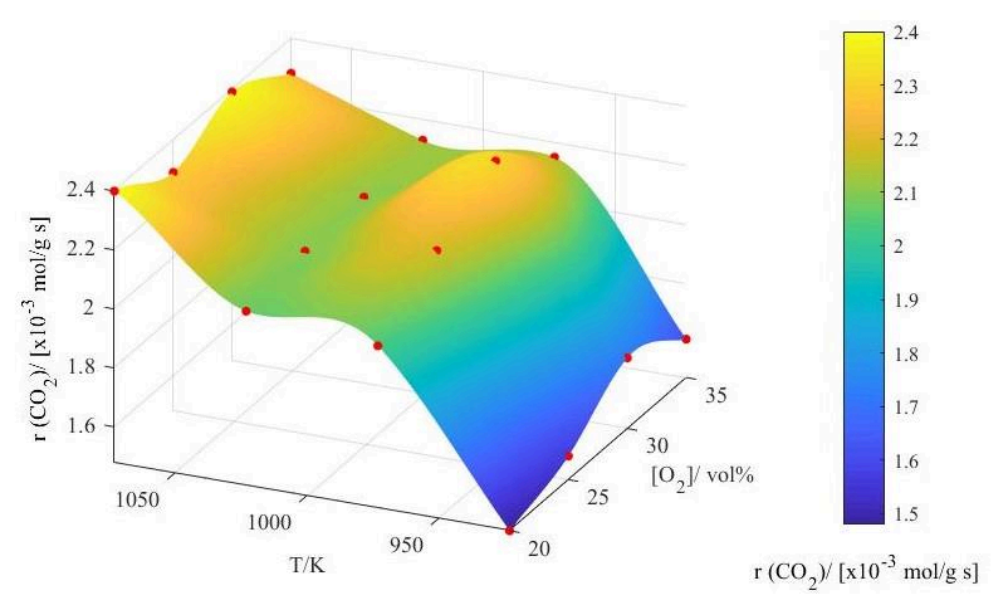

1 Figure 3. Rate of $\mathrm{CO}_{2}$ production $v s$. temperature and $\mathrm{O}_{2}$ concentration for the air combustion tests.

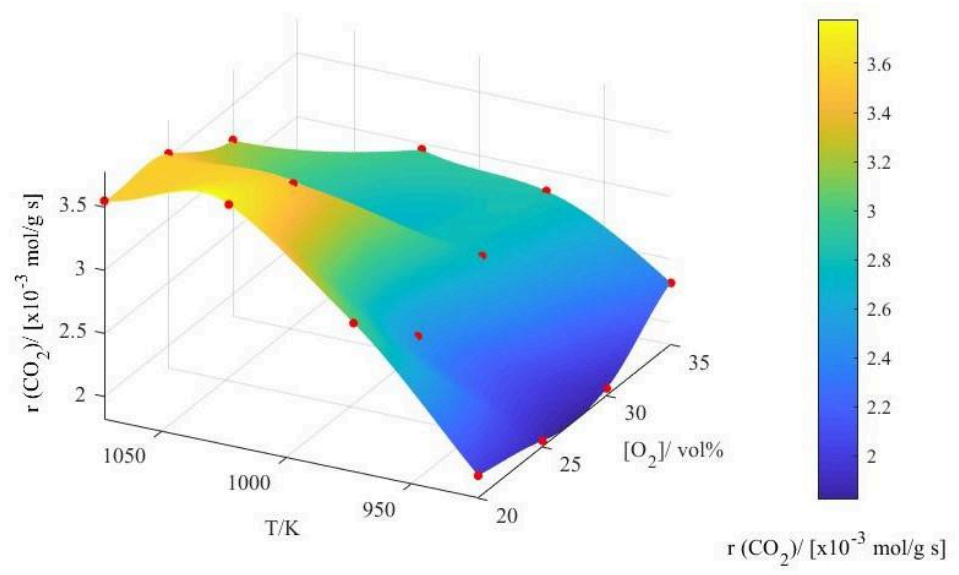

Figure 4. Rate of $\mathrm{CO}_{2}$ production $v s$. temperature and $\mathrm{O}_{2}$ concentration for the oxy-fuel combustion tests.

\subsection{Order of reaction}

The combustion process can be described by the rate equation $r=k\left[\mathrm{O}_{2}\right]^{n}$ (Fennell et al., 2009), where $r$ is the rate of combustion, $k$ is the rate constant, $\left[\mathrm{O}_{2}\right]$ is the molar concentration of oxygen, and $n$ is the reaction order.

In air combustion conditions, the apparent order of reaction obtained here is approximately zero (see Figure 5). It was found, at all temperatures investigated, that the rate of biomass combustion was not influenced by an increase in oxygen concentration from 20 to $35 \mathrm{vol} \%$. This zero-order trend was also seen in the oxy-fuel combustion tests (Figure 6) at the lower bed temperatures (923-973 K), but at the higher bed temperatures (1023-1073 K) the order of was found to be -0.4 , which appears to be caused by errors in the $\mathrm{CO}_{2}$ concentration measurement at oxygen concentrations close to the maximum range of the analyser (40 vol\%). 


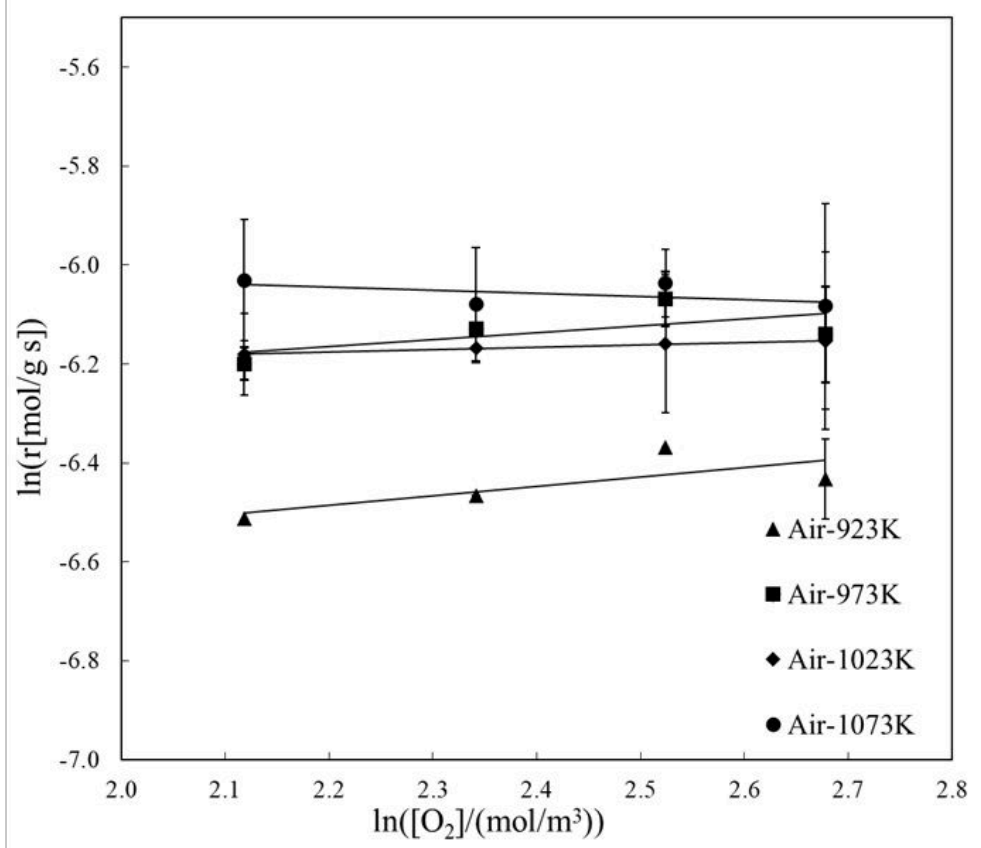

Figure 5. $\ln (r)$ vs. $\ln \left[\mathrm{O}_{2}\right]$ in air combustion tests. At conditions of $923-1073 \mathrm{~K}, 20-35$ vol\% $\mathrm{O}_{2}, 0.02 \mathrm{~g}( \pm 2 \%)$ sample, $U / U_{m f}=3$, and $1 \operatorname{bar}(\mathrm{a})$. The error bars show the standard deviation between three repeats.

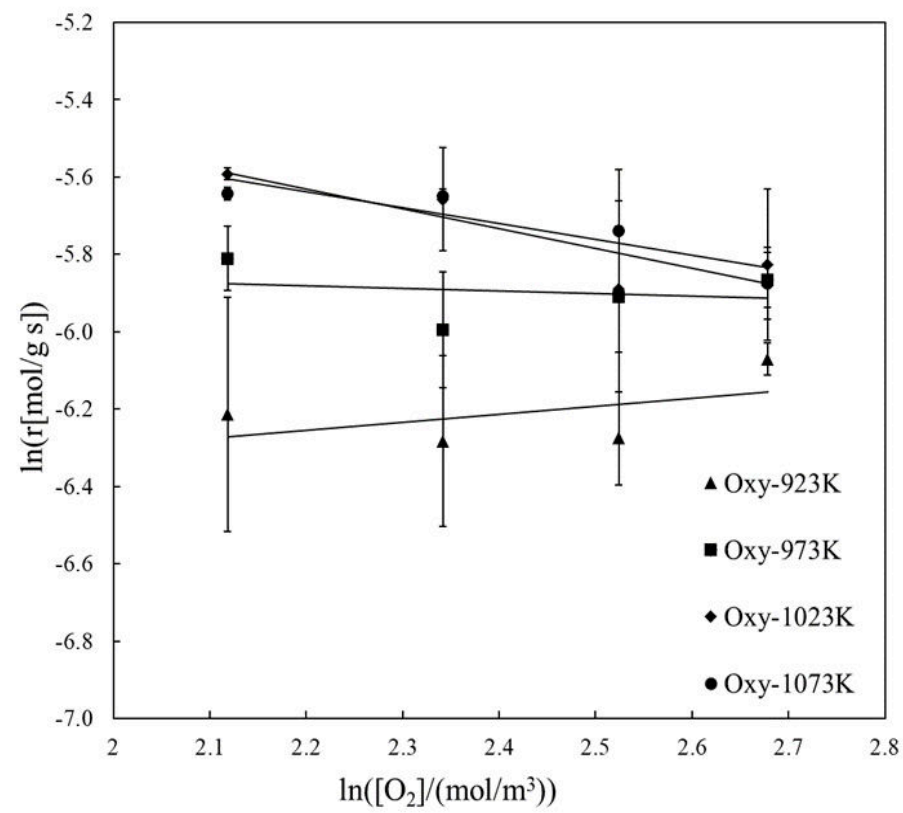

Figure 6. $\ln (r)$ vs. $\ln \left[\mathrm{O}_{2}\right]$ in oxy-fuel combustion tests. At conditions of $923-1073 \mathrm{~K}, 20-35 \mathrm{vol} \% \mathrm{O}_{2}, 0.02 \mathrm{~g}$ $( \pm 2 \%)$ sample, $\mathrm{U} / \mathrm{U}_{\mathrm{mf}}=3$, and 1 bar(a). The error bars show standard deviation between three repeats. 


\subsection{Activation Energies}

The activation energies and pre-exponential factors under air and oxy-fuel combustion were derived using the Arrhenius equation. The rate constants, $k$, were calculated over the $20-35$ vol $\% \mathrm{O}_{2}$ range and across the bed temperature range of 923-1073 K under air and oxy-fuel combustion conditions. The average activation energy (Ea) for air combustion was found to be $18.95 \mathrm{~kJ} / \mathrm{mol}$ and $26.93 \mathrm{~kJ} / \mathrm{mol}$ for oxy-fuel combustion. This trend is in agreement with the work of Li et al. (2019).

It should also be noted that both activation energies in this test are about one-third of previous activation energies of coal or biomass char combustion found in the literature (Fennell et al., 2009; Gövert et al., 2017; Li et al., 2014; Yurdakul Yorulmaz and Atimtay, 2009), likely because of measured rates of $\mathrm{CO}_{2}$ from both volatile and char combustion. This, therefore, represents the apparent activation energy of biomass combustion instead of the intrinsic activation energy of volatile combustion or char combustion.

\subsection{Shrinking Core Model Validation}

The shrinking unreacted core model has been fitted to the data for fuel carbon conversion to $\mathrm{CO}_{2}$, in order to identify the likely mechanisms for combustion. The process of biomass combustion was simplified, as Reaction (R1):

$$
\mathrm{C}_{(\mathrm{s})+} \mathrm{O}_{2(\mathrm{~g})} \rightarrow \mathrm{CO}_{2(\mathrm{~g})}
$$

In this process, oxygen first diffuses through the gas film surrounding the fuel particle and then reacts at its surface. The produced $\mathrm{CO}_{2}$ then diffuses back through the product ash layer and fresh $\mathrm{O}_{2}$ diffuses in through the product layer. External film and ash layer diffusion can be assumed to be negligible here, because of the relatively high fluidisation velocity $\left(U / U_{\mathrm{mf}}=3\right)$. The rate of mass transfer of oxygen to the exterior of the spherical fuel particles is calculated to be approximately $4.5 \times 10^{-7} \mathrm{~mol} / \mathrm{g} \mathrm{s}$ (See Supporting Materials for more details), which is far less than the measured reaction rate $\left(1.48 \times 10^{-3}\right.$ at $973 \mathrm{~K}$ in air conditions). The conversion and dimensionless time equations for a reaction-controlled shrinking unreacted core model on a spherical particle are as follows:

$$
\begin{gathered}
\frac{t}{\tau}=1-(1-X)^{1 / 3} \\
\tau=\frac{\rho R p}{b k s C_{A g}}
\end{gathered}
$$

Equation 1

Equation 2

where $t$ is the instantaneous reaction time point, $\tau$ is the total reaction time, $X$ is the fuel conversion, $b$ is the stoichiometric coefficient, $C_{A g}$ is the concentration of A in bulk gas, $\rho$ is the molar density of the particle, $R p$ is the radius of the particle, and $k s$ is the reaction rate constant.

Fitting the experimental data to this model involved minimising the sum of the squared errors between the experimental and modelled conversions, whilst adjusting the value of the rate constant, $k s$. The fitting was carried 
out up to the final experimental C-to- $\mathrm{CO}_{2}$ conversion value. The conversion-time data obtained from the shrinking core model were compared with the experimental results, as shown in Figures 7-10. It was found that the reactioncontrolled shrinking core model prediction closely matched the experimental results, with the largest deviations occurring at the lowest levels of conversion. This difference at the initial phase of reaction appears to be caused by external mass transport smoothing effects in the tubing post-reactor. The experiments with the lowest carbon conversions were probably governed by other factors: incomplete combustion or more likely fine particles elutriating from the reactor before fully reacting.

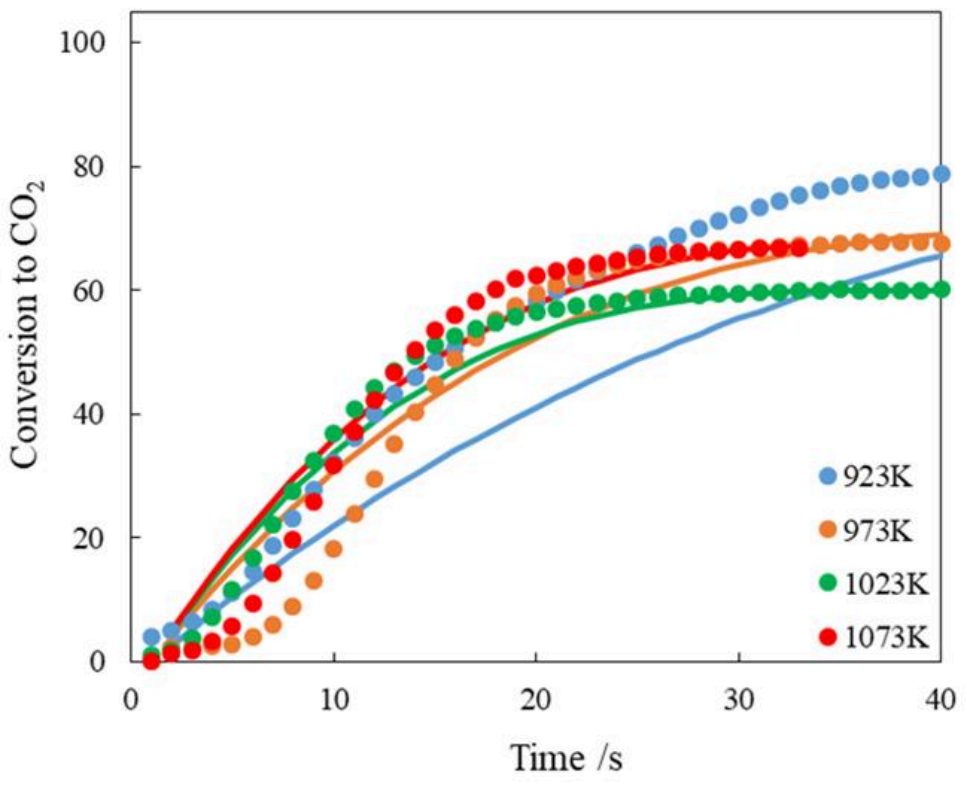

Figure 7. Comparison of experimental results and model predictions at $25 \mathrm{vol} \% \mathrm{O}_{2}$, bed temperature $923-1073 \mathrm{~K}$ under air combustion of wood. (Points: experimental results. Solid lines: shrinking core model predictions). 


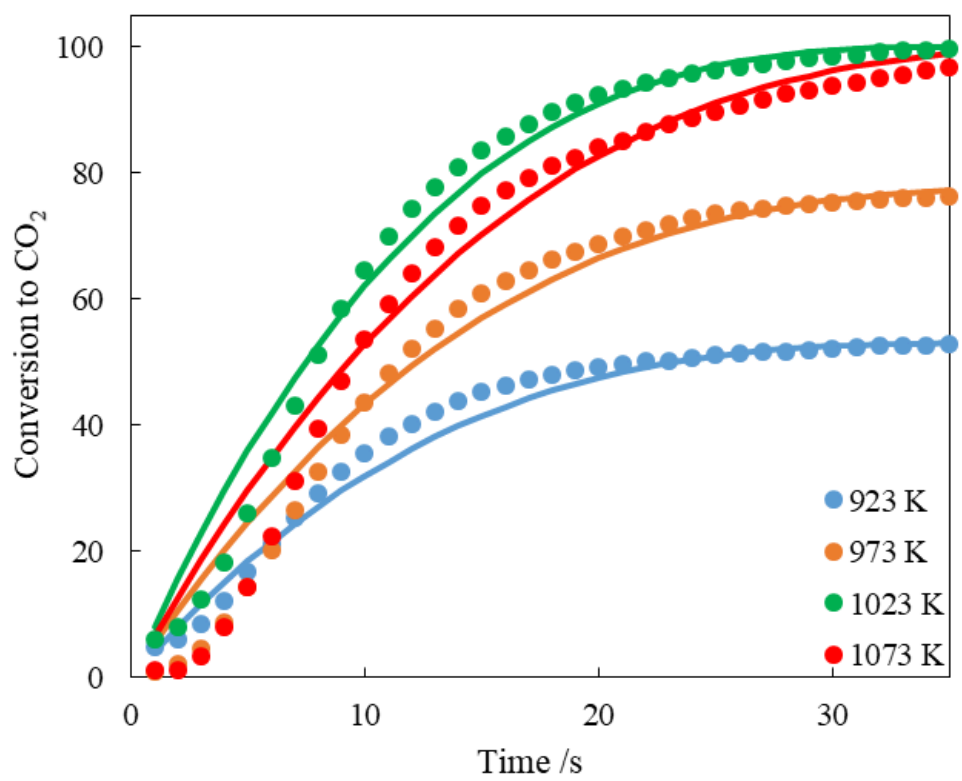

Figure 8. Comparison of experimental results and model predictions at $25 \mathrm{vol} \% \mathrm{O}_{2}$, bed temperature $923-1073 \mathrm{~K}$ under oxy-fuel combustion of wood. (Points: experimental results. Solid lines: shrinking core model predictions).

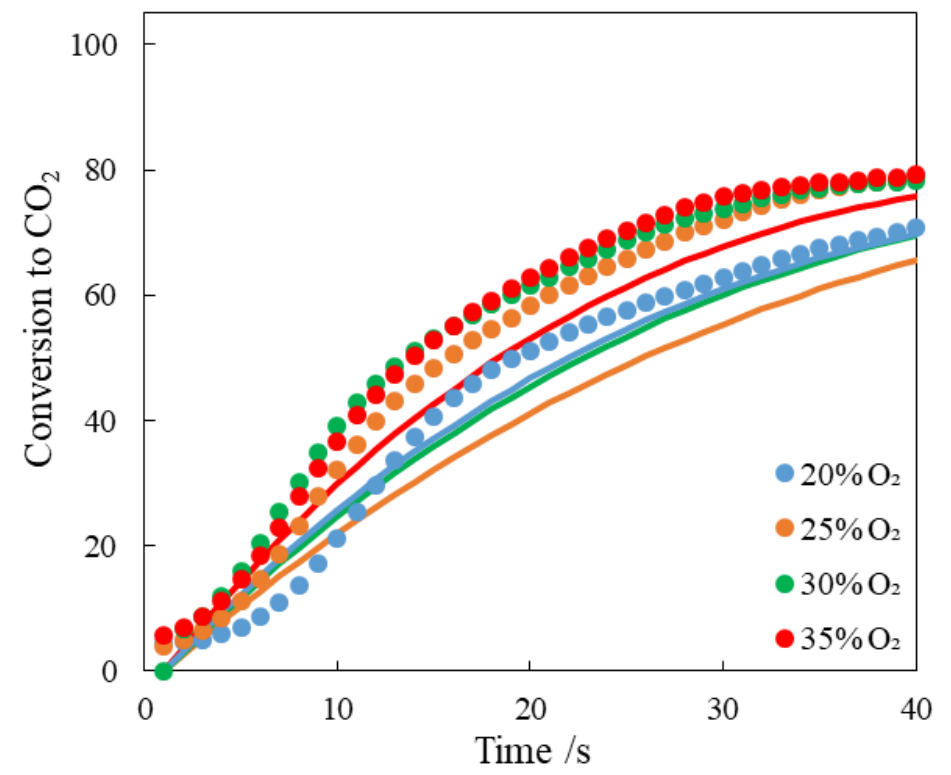

Figure 9. Comparison of experimental results and model predictions at $20-35 \mathrm{vol} \% \mathrm{O}_{2}$, bed temperature $923 \mathrm{~K}$ under air combustion of wood. (Points: experimental results. Solid lines: shrinking core model predictions). 


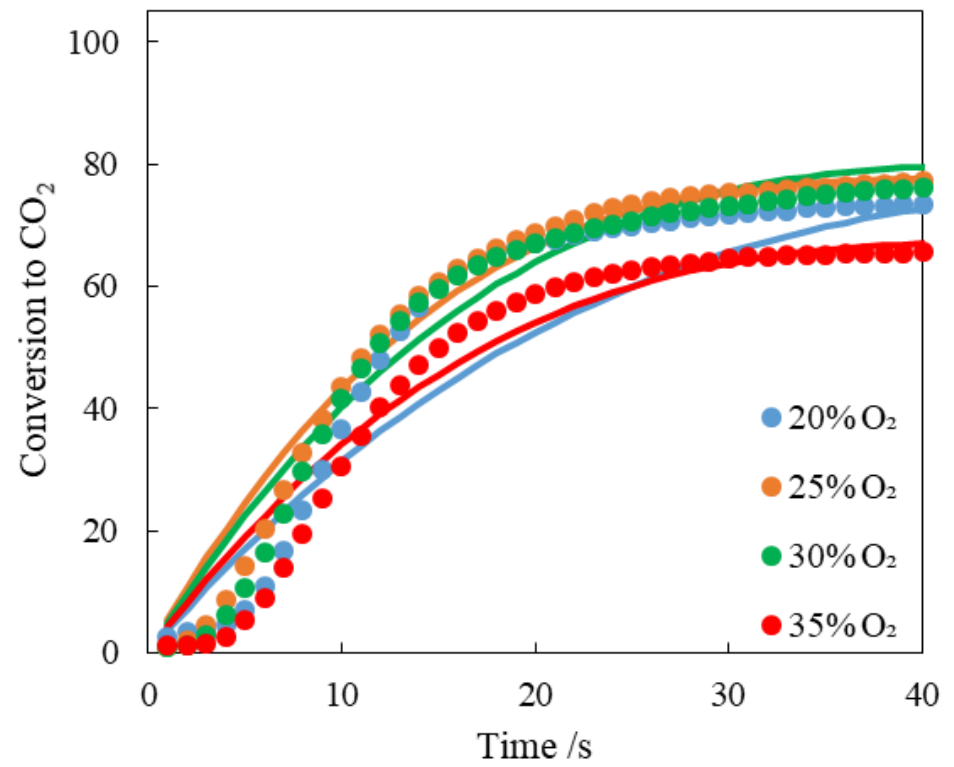

Figure 10. Comparison of experimental results and model predictions at 20-35 vol\% $\mathrm{O}_{2}$, bed temperature $923 \mathrm{~K}$ under oxy-fuel combustion of wood. (Points: experimental results. Solid lines: shrinking core model predictions).

Table 2 presents the reaction rate constants determined by the shrinking core model. These have similar trends to those measured from the experimental tests, having an average difference of 50\%. This difference was primarily due to the experimental data in the initial portion of the reaction, which have a marked inflection. Again, this difference was likely a result of the tubing length post-reactor causing a smoothing effect on the data; additionally, the numerical method of removing the blank feed from the data may have impacted the data. Furthermore, the shrinking core model to fit the experimental data by Reaction (R1) neglected more complicated reactions that occur simultaneously due to the presence of other chemical species in the fuel, such as hydrogen, oxygen, nitrogen, sulphur and moisture. The combustion process is probably also slightly affected by ash layer diffusion effects. 
Table 2. Shrinking core model and experimental observed rate constants. Experiments varying bed temperature were conducted at a constant $\mathrm{O}_{2}$ concentration of $25 \mathrm{vol} \%$, and experiments varying oxygen concentrations were conducted at $923 \mathrm{~K}$.

\begin{tabular}{ccccc}
\hline & \multicolumn{2}{c}{$k \exp (\mathbf{m} / \mathbf{s})$} & \multicolumn{2}{c}{$\boldsymbol{k s}(\mathbf{m} / \mathbf{s})$} \\
\hline $\begin{array}{c}\text { Bed temperature } \\
(\mathrm{K})\end{array}$ & Air & Oxy-fuel & Air & Oxy-fuel \\
\hline 923 & 0.074 & 0.093 & 0.044 & 0.102 \\
973 & 0.109 & 0.124 & 0.079 & 0.097 \\
1023 & 0.105 & 0.174 & 0.115 & 0.118 \\
1073 & 0.114 & 0.176 & 0.314 & 0.100 \\
\hline $\begin{array}{c}\text { Oxygen } \\
\text { concentration }(\%)\end{array}$ & Air & Oxy-fuel & Air & Oxy-fuel \\
\hline 20 & 0.074 & 0.150 & 0.069 & 0.082 \\
25 & 0.074 & 0.093 & 0.044 & 0.102 \\
30 & 0.086 & 0.136 & 0.042 & 0.071 \\
35 & 0.080 & 0.141 & 0.044 & 0.061 \\
\hline
\end{tabular}

\subsection{Discussion}

In this work, the apparent kinetics of air and oxy-fuel combustion of raw biomass were calculated by measuring the rate of gas concentration change. It was found that the activation energy of biomass combustion in this work was about one-third that for wood char combustion found in previous work (Wang et al., 2015). The different chemical and physical properties (due to the presence of volatile hemicellulose and cellulose) and different combustion process can explain the difference between the woody biomass and its char.

Raw biomass contains a larger amount of volatile matter (78.3 wt \%) than that of char (15.0 wt $\%)$, which when added to a hot reactor, quickly devolatilises and begins to combust in the gaseous phase, enhancing the char oxidation reactions. In addition, the particle size and surface of biomass char are also different from the raw biomass due to the devolatilisation and swelling in the char generation process (Gövert et al., 2017; Li et al., 2014). A decrease in volatile matter content of biomass fuels reduces its reactivity, which was demonstrated by Li et al. (2014), who showed that the reactivity of biomass decreases with the increase of degree of torrefaction.

Another reason for the lower apparent activation energy for biomass combustion relative to char combustion found in this work is the different reaction processes between biomass and char. The process of biomass combustion consists of heating and drying, devolatilisation, volatile matter combustion, and char combustion. Previous work, 
measuring the kinetics of char combustion using a FBR found that the reaction was controlled predominantly by the kinetics of the oxidation reactions $(120 \mathrm{~kJ} / \mathrm{mol})$ and secondly by the oxygen diffusion control $(60 \mathrm{~kJ} / \mathrm{mol})$ (Bews et al., 2001; Fennell et al., 2009). In this work, when the biomass was injected into the reactor, the process of devolatilisation and volatile matter combustion overlapped with the char combustion. The measured $\mathrm{CO}_{2}$ cannot differentiate whether $\mathrm{CO}_{2} / \mathrm{CO}$ came from char combustion or from volatile matter combustion, Instead, it describes the total production of $\mathrm{CO}$ and $\mathrm{CO}_{2}$ from both the volatile matter and char combustion. This method was also used by Shan et al. (2018), who investigated biomass combustion behaviour using a visualisation method. It was observed that there were two separate processes for volatile matter and char combustion for biomass and the duration of those processes is based on the fixed carbon-to-volatile matter mass ratio of the biomass (Bai et al., 2017; Shan et al., 2018). It was also concluded that the devolatilisation and volatile matter combustion not only influenced the time to complete burnout, but also had a large impact on the measured biomass combustion kinetics by the FBR method.

The reaction-controlled shrinking core model was able to fit the experimental data relatively well; however, the calculated reaction rate constants tended to be slightly lower than those obtained from the experimental data due to the complex biomass combustion processes and the assumptions made in fitting the model to the data (considered only fuel carbon to $\mathrm{CO}_{2}$ reactions).

\section{Conclusions}

The air and oxy-fuel combustion reactions of raw woody biomass have been investigated in a bench-scale, spouted fluidised-bed reactor. Combustion experiments were conducted under the different oxygen concentrations (20-35 vol\%), and across a range of bed temperatures (923-1073 K). The shrinking core model was fitted to the carbon conversion data and well represented the reaction kinetics observed, with the largest deviation occurring in the initial stages of combustion.

The experimental results indicate that the measured rate of oxy-fuel combustion is higher $(\sim 37.5 \%)$ than that of air combustion under the same conditions. The apparent orders of reaction for air and oxy-fuel combustion of biomass in the spouted fluidised-bed reactor were found to be approximately zero. The activation energies for air and oxy-fuel combustion of biomass were found to be $18.95 \mathrm{~kJ} / \mathrm{mol}$ and $26.93 \mathrm{~kJ} / \mathrm{mol}$, respectively. Comparing those with previous work, the activation energy of raw woody biomass combustion in this work is less than that of wood char combustion. This can be explained by the fact that the devolatilisation and volatile combustion of woody biomass overlap the char combustion. Therefore, the measured $\mathrm{CO}_{2}$ rate indicates the apparent kinetics of woody biomass combustion - it cannot represent the corrected reaction rates of any process.

The issue of pressurised sample injection on the accurate measurement of $\mathrm{CO}_{2}$ concentration was resolved by factoring in the effects of blank (no sample) injections. Ideally, the apparent kinetics of air and oxy-fuel 
combustion of biomass should be measured using biomass char in the spouted fluidised-bed reactor with the advantages of high heating rates, and minimised heat and mass transfer resistances.

\section{Acknowledgements}

PTC and EJA would like to thank the EPSRC and UKCCSRC for financial support through grant EP/P026214/1. YYL would like to acknowledge the financial support from the Cranfield University Energy and Power research bursary. Data from this research can be accessed through Cranfield University's data storage and recovery site Cranfield Online Research Data (CORD) - https://cranfield.figshare.com/.

\section{Nomenclature}

$\begin{array}{ll}\text { Ea } & \text { Activation energy }(\mathrm{kJ} / \mathrm{mol}) \\ k & \text { Kinetic rate constant }\left(\mathrm{s}^{-1}\right) \\ k s & \text { Reaction rate constant }- \text { modelled }\left(\mathrm{m} \mathrm{s}^{-1}\right) \\ k \text { exp } & \text { Reaction rate constant }- \text { experimental }\left(\mathrm{m} \mathrm{s}^{-1}\right) \\ n & \text { Reaction order } \\ \rho & \left.\text { Molar density (mol } \mathrm{m}^{-3}\right) \\ r & \text { Initial rate of combustion }\left(\mathrm{mol} \mathrm{m}^{-3} \mathrm{~s}^{-1}\right) \\ R p & \text { Radius of particle (m) } \\ t & \text { Instantaneous time point (s) } \\ \tau & \text { Total reaction time (s) } \\ U & \text { Superficial velocity of fluidising gas }\left(\mathrm{m} \mathrm{s}^{-1}\right) \\ U_{\mathrm{mf}} & \text { Minimum fluidisation velocity }\left(\mathrm{m} \mathrm{s}^{-1}\right) \\ X & \text { Fuel conversion (\%) }\end{array}$

$\begin{array}{ll}\text { Abbreviations } \\ \text { BECCS } & \text { Bio-energy with carbon capture and storage } \\ \text { CCS } & \text { Carbon capture and storage } \\ \text { DAQ } & \text { Data acquisition } \\ \text { DTR } & \text { Drop tube reactor } \\ \text { EFR } & \text { Entrained-flow reactor } \\ \text { FBR } & \text { Fluidised-bed reactor }\end{array}$


MFCs Mass flow controllers

TGA Thermogravimetric analysis

\section{References}

3 Álvarez, L., Gharebaghi, M., Pourkashanian, M., Williams, A., Riaza, J., Pevida, C., Pis, J.J., Rubiera, F., 2011. CFD modelling of oxy-coal combustion in an entrained flow reactor. Fuel Process. Technol. 92, 1489-1497. https://doi.org/10.1016/j.fuproc.2011.03.010

Bai, X., Lu, G., Bennet, T., Sarroza, A., Eastwick, C., Liu, H., Yan, Y., 2017. Combustion behavior profiling of single pulverized coal particles in a drop tube furnace through high-speed imaging and image analysis. Exp. Therm. Fluid Sci. 85, 322-330. https://doi.org/10.1016/j.expthermflusci.2017.03.018

9 Bews, I.M., Hayhurst, A.N., Richardson, S.M., Taylor, S.G., 2001. The order, Arrhenius parameters, and mechanism of the Reaction Between Gaseous Oxygen and Solid Carbon. Combust Flame, 124 (2001), pp. 231-245.

Bui, M., Adjiman, C.S., Bardow, A., Anthony, E.J., Boston, A., Brown, S., Fennell, P.S., Fuss, S., Galindo, A., Hackett, L.A., Hallett, J.P., Herzog, H.J., Jackson, G., Kemper, J., Krevor, S., Maitland, G.C., Matuszewski, M., Metcalfe, I.S., Petit, C., Puxty, G., Reimer, J., Reiner, D.M., Rubin, E.S., Scott, S.A., Shah, N., Smit, B., Trusler, J.P.M., Webley, P., Wilcox, J., Mac Dowell, N., 2018. Carbon capture and storage (CCS): The way forward. Energy Environ. Sci. https://doi.org/10.1039/c7ee02342a

Clough, P.T., Boot-Handford, M.E., Zheng, L., Zhang, Z., Fennell, P.S., 2018. Hydrogen production by sorption enhanced steam reforming (SESR) of biomass in a fluidised-bed reactor using combined multifunctional particles. Materials (Basel). 11. https://doi.org/10.3390/ma11050859

Duan, L., Duan, Y., Zhao, C., Anthony, E.J., 2015. NO emission during co-firing coal and biomass in an oxy-fuel circulating fluidized bed combustor. Fuel 150, 8-13. https://doi.org/10.1016/j.fuel.2015.01.110

Fennell, P.S., Dennis, J.S., Hayhurst, A.N., 2009. The order with respect to oxygen and the activation energy for the burning of an anthracitic char in $\mathrm{O}_{2}$ in a fluidised bed, as measured using a rapid analyser for $\mathrm{CO}$ and 
$\mathrm{CO}_{2}$. Proc. Combust. Inst. 32 II, 2051-2058. https://doi.org/10.1016/j.proci.2008.06.097

Fennell, P.S., Hayhurst, A.N., Dennis, J.S., Kadchha, S., Lee, H.-Y., 2005. The kinetics of oxidation of chars from three different coals, as measured in fluidized beds, in: 18th International Conference on Fluidized Bed Combustion. ASME, pp. 881-894. https://doi.org/10.1115/FBC2005-78073

Fennell, P.S., Kadchha, S., Lee, H.-Y., Dennis, J.S., Hayhurst, A.N., 2007. The measurement of the rate of burning of different coal chars in an electrically heated fluidised bed of sand. Chem. Eng. Sci. 62, 608-618. https://doi.org/10.1016/J.CES.2006.09.024

Gil, M.V., Riaza, J., Álvarez, L., Pevida, C., Pis, J.J., Rubiera, F., 2012. Kinetic models for the oxy-fuel combustion of coal and coal/biomass blend chars obtained in $\mathrm{N}_{2}$ and $\mathrm{CO}_{2}$ atmospheres. Energy 48, 510-518. https://doi.org/10.1016/J.ENERGY.2012.10.033

Gövert, B., Pielsticker, S., Kreitzberg, T., Habermehl, M., Hatzfeld, O., Kneer, R., 2017. Measurement of reaction rates for pulverized fuel combustion in air and oxyfuel atmosphere using a novel fluidized bed reactor setup. Fuel 201, 81-92. https://doi.org/10.1016/J.FUEL.2017.03.009

Haustein, H.D., Kreitzberg, T., Gövert, B., Massmeyer, A., Kneer, R., 2015. Establishment of kinetic parameters of particle reaction from a well-stirred fluidized bed reactor. Fuel 158, 263-269. https://doi.org/10.1016/J.FUEL.2015.05.038

Kim, G.M., Kim, J.P., Lisandy, K.Y., Jeon, C.H., 2017. Experimental model development of oxygen-enriched combustion kinetics on porous coal char and non-porous graphite. Energies 10. https://doi.org/10.3390/en10091436

Li, J., Bonvicini, G., Tognotti, L., Yang, W., Blasiak, W., 2014. High-temperature rapid devolatilization of biomasses with varying degrees of torrefaction. Fuel 122, 261-269. https://doi.org/10.1016/j.fuel.2014.01.012

Li, J., Paul, M.C., Younger, P.L., Watson, I., Hossain, M., Welch, S., 2015. Characterization of biomass combustion at high temperatures based on an upgraded single particle model. Appl. Energy 156, 749-755. https://doi.org/10.1016/j.apenergy.2015.04.027

Liu, H., 2009. Combustion of Coal Chars in $\mathrm{O}_{2} / \mathrm{CO}_{2}$ and $\mathrm{O}_{2} / \mathrm{N}_{2}$ Mixtures: A comparative study with non- 
isothermal Thermogravimetric Analyzer (TGA) Tests. https://doi.org/10.1021/ef9002928

Morin, M., Pécate, S., Hémati, M., 2018. Kinetic study of biomass char combustion in a low temperature fluidized bed reactor. Chem. Eng. J. 331, 265-277. https://doi.org/10.1016/J.CEJ.2017.08.063

Mueller, A., Haustein, H.D., Stoesser, P., Kreitzberg, T., Kneer, R., Kolb, T., 2015. Gasification kinetics of biomass-and fossil-based fuels: comparison study using fluidized bed and thermogravimetric analysis. https://doi.org/10.1021/acs.energyfuels.5b01123

Seddighi, S., Clough, P.T., Anthony, E.J., Hughes, R.W., Lu, P., 2018. Scale-up challenges and opportunities for carbon capture by oxy-fuel circulating fluidized beds. Appl. Energy 232, 527-542. https://doi.org/10.1016/j.apenergy.2018.09.167

Shan, L., Kong, M., Bennet, T.D., Sarroza, A.C., Eastwick, C., Sun, D., Lu, G., Yan, Y., Liu, H., 2018. Biomass and bioenergy studies on combustion behaviours of single biomass particles using a visualization method. Biomass and Bioenergy 109, 54-60. https://doi.org/10.1016/j.biombioe.2017.12.008

Sher, F., Pans, M.A., Sun, C., Snape, C., Liu, H., 2018. Oxy-fuel combustion study of biomass fuels in a $20 \mathrm{~kW}$ th fluidized bed combustor. Fuel 215, 778-786. https://doi.org/10.1016/j.fuel.2017.11.039

Tolvanen, H., Keipi, T., Raiko, R., 2016. A study on raw, torrefied, and steam-exploded wood: Fine grinding, drop-tube reactor combustion tests in $\mathrm{N}_{2} / \mathrm{O}_{2}$ and $\mathrm{CO}_{2} / \mathrm{O}_{2}$ atmospheres, particle geometry analysis, and numerical kinetics modeling. Fuel 176, 153-164. https://doi.org/10.1016/j.fuel.2016.02.071

Tolvanen, H., Raiko, R., 2014. An experimental study and numerical modeling of combusting two coal chars in a drop-tube reactor: A comparison between $\mathrm{N}_{2} / \mathrm{O}_{2}, \mathrm{CO}_{2} / \mathrm{O}_{2}$, and $\mathrm{N}_{2} / \mathrm{CO}_{2} / \mathrm{O}_{2}$ atmospheres. Fuel 124, 190-201. https://doi.org/10.1016/J.FUEL.2014.01.103

Varol, M., Symonds, R., Anthony, E.J., Lu, D., Jia, L., Tan, Y., 2018. Emissions from co-firing lignite and biomass in an oxy-fired CFBC. Fuel Process. Technol. 173, 126-133. https://doi.org/10.1016/j.fuproc.2018.01.002

Wang, X., Hu, Z., Deng, S., Wang, Y., Tan, H., 2015. Kinetics investigation on the combustion of biochar in $\mathrm{O}_{2} / \mathrm{CO}_{2}$ atmosphere. Environ. Prog. Sustain. Energy. https://doi.org/10.1002/ep.12063

Wen, C.Y., Yu, Y.H., 1966. A generalized method for predicting the minimum fluidization velocity. AIChE J. 12, 610-612. https://doi.org/10.1002/aic.690120343 
Yurdakul Yorulmaz, S., Atimtay, A.T., 2009. Investigation of combustion kinetics of treated and untreated waste wood samples with thermogravimetric analysis. Fuel Process. Technol. 90, 939-946. https://doi.org/10.1016/j.fuproc.2009.02.010

Zhu, Q., 2013. Developments in fluidised bed combustion technology. IEA 